\title{
Spontaneous regression of solitary osteochondromas in children: An option to consider in clinical practice
}

\author{
María Durán-Serrano, $\mathrm{MD}^{1}{ }^{(D)}$, Victoria Eugenia Gómez-Palacio, MD, PhD'ㄹ, \\ Isabel Parada-Avendaño, $\mathrm{MD}^{1}{ }^{1}$, Jorge Gil-Albarova, $\mathrm{MD}, \mathrm{PhD}^{1,2}(\mathbb{D}$ \\ ${ }^{1}$ Department of Orthopedic and Trauma Surgery, Miguel Servet University Hospital, Zaragoza, Spain \\ ${ }^{2}$ Department of Surgery, Faculty of Medicine, University of Zaragoza, Zaragoza, Spain
}

Solitary osteochondromas are neoplasms that are developed during bone growth by endochondral ossification. These benign tumors belong to the family of cartilaginous histogenesis tumors and represents $90 \%$ of all forms of exostoses. ${ }^{[1]}$

A review of the current literature reveals that spontaneous regression of osteochondromas is rarely documented. In this article, we present four cases of a solitary osteochondroma resolution in the light of literature data.

\section{CASE REPORT}

Case 1- A four-year-old boy was admitted with a mass in the right knee. There was no relevant medical history or associated trauma. Physical examination revealed a hard, smooth, non-tender, non-mobile mass over the medial aspect of the

Received: February 22, 2021

Accepted: May 03, 2021

Published online: June 11, 2021

Correspondence: María Durán-Serrano, MD. Orthopedic and Trauma Surgery Service, Miguel Servet University Hospital, Avda. Isabel la Católica 1-3, 50009 Zaragoza, Spain.

E-mail: duranserranomaria@gmail.com

Doi: $10.52312 /$ jdrs.2021.140

Citation: Durán-Serrano $M$, Gómez-Palacio VE, ParadaAvendaño I, Gil-Albarova J. Spontaneous regression of solitary osteochondromas in children: An option to consider in clinical practice. Jt Dis Relat Surg 2021;32(2):514-520.

(92021 All right reserved by the Turkish Joint Diseases Foundation

This is an open access article under the terms of the Creative Commons Attribution-NonCommercial License, which permits use, distribution and reproduction in any medium, provided the original work is properly cited and is not used for commercial purposes (http://creativecommons.org/licenses/by-nc/4.0/).

\section{ABSTRACT}

Osteochondromas are neoplasm that belong to the family of cartilaginous histogenesis tumors and represent $90 \%$ of all forms of exostoses. As most osteochondromas are asymptomatic, underdiagnosis is frequent. Symptomatic forms usually manifest before the age of 20 years, and the most common symptoms are pain and the detection of a bony mass. Herein, we report four cases of spontaneous regression of solitary osteochondromas in the light of literature. We consider that orthopedic surgeons should take into account the possibility of spontaneous regression of these tumors, before recommending surgery. Symptoms are usually mild and we recommend following these patients with X-ray and physical examination annually.

Keywords: Exostosis, osteochondroma, spontaneous regression.

distal femur. He maintained a normal range of motion in all planes. There was no neurovascular compromise. Radiological evaluation of the knee showed a broad-based sessile osteochondroma emanating from the distal femur metaphysis without any abnormal calcifications of the cartilaginous cap. It measured $19.7 \mathrm{~mm}$ in diameter at the base and projected $12.5 \mathrm{~mm}$ away from the cortex (Figure 1). Recommendation was observation with follow-up annually. At the age of seven, the tumor was undetectable neither physically nor radiologically. Repeated physical examination showed no loss of motion or neurovascular compromise.

A written informed consent was obtained from the parents and/or legal guardians of the patient.

Case 2- A 10-year-old boy presented with a lump on his left upper arm. Physical examination revealed a bony hard mass on the anterior side of the upper arm. Radiographs showed a sessile osteochondroma on the proximal humerus. It measured $30.14 \mathrm{~mm}$ in diameter at the base and projected $14 \mathrm{~mm}$ away 
from the cortex (Figure 2). The patient did not report pain with regard to the osteochondroma, although the bony prominence was palpable. There was no neurovascular compromise. Of note, the patient had a medical history of medulloblastoma, hypothyroidism, and growth retardation. Annual follow-up showed clinical and radiographic spontaneous regression of the lesion within three years.

A written informed consent was obtained from the parents and/or legal guardians of the patient.

Case 3- A 10-year-old boy, with no relevant medical history, was admitted to our orthopedic clinic for the evaluation of a mass in his left distal femur. The mass neither caused him pain nor limited his activities. Physical examination showed no tenderness to palpation over thelesion. Neurovascular examination showed no compromise to the distal extremity. A solitary sessile osteochondroma was radiographically observed on the posteromedial aspect of the distal femoral metaphysis, it measured $52 \mathrm{~mm}$ in diameter from the base and projected $19 \mathrm{~mm}$ away from the cortex (Figure 3). He was clinically and radiologically followed at 12-month intervals. An increase of the lesion size was noticed on X-ray at one-year follow-up; however, it did not produce any musculoskeletal symptoms. In the following four years, it progressively regressed spontaneously starting to shrink at the age of 12 and resolved by the age of 15 .

A written informed consent was obtained from the parents and/or legal guardians of the patient.

Case 4- An 11-year-old boy presented with a lump on his right upper arm. Physical examination revealed a bony hard mass on the lateral side of the
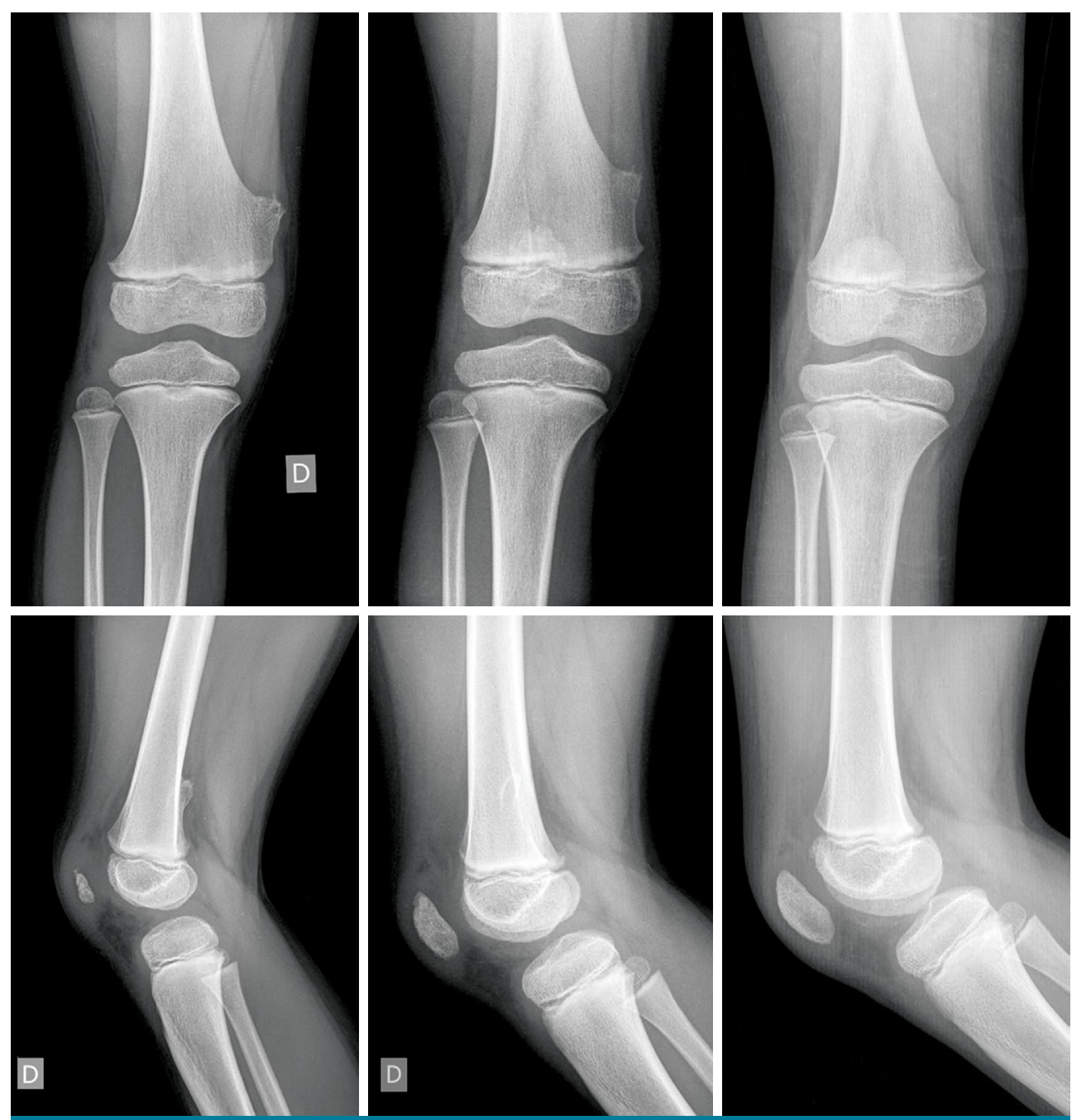

FIGURE 1. Anteroposterior and lateral X-rays of the right knee. A four-year-old boy with an osteochondroma in distal femur followed by X-ray annually, until the tumor vanished. 


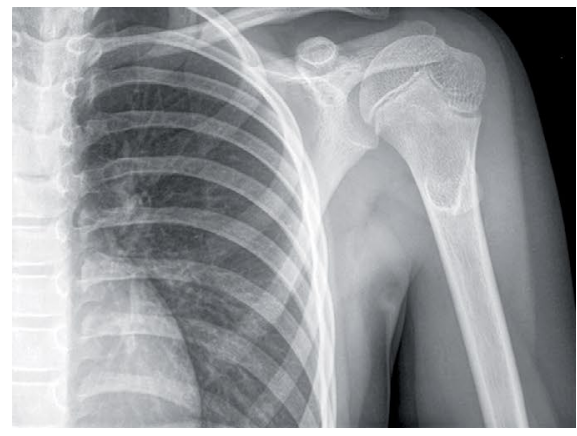

I
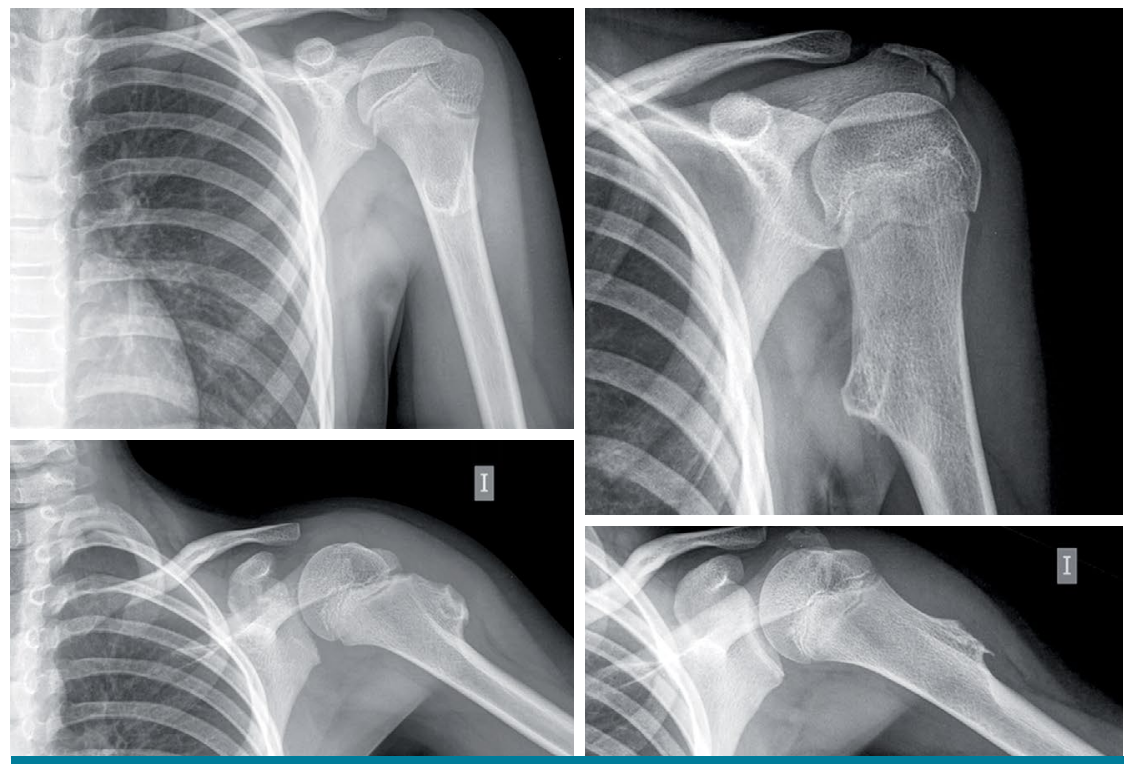

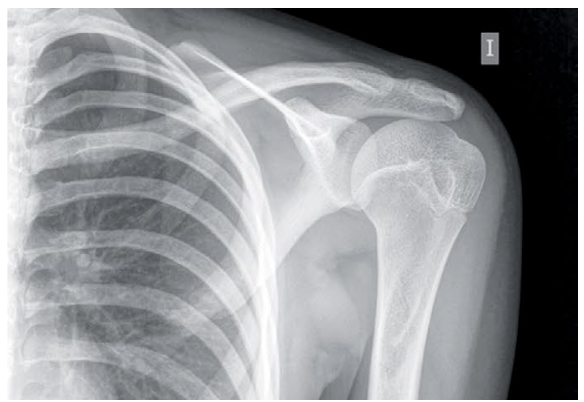

FIGURE 2. Anteroposterior radiographies of the left shoulder. A 10-year-old boy with an osteochondroma in proximal humerus followed by X-ray for three consecutive years.

upper arm. Radiographs showed a pedunculated osteochondroma on the proximal humerus. It measured $23.74 \mathrm{~mm}$ in diameter at the base and projected $17.25 \mathrm{~mm}$ away from the cortex (Figure 4). The patient did not report pain with regard to the osteochondroma, although the bony prominence was palpable. There was no neurovascular compromise. Annual follow-up showed clinical and radiographic spontaneous regression of the lesion within four years.

A written informed consent was obtained from the parents and/or legal guardians of the patient.
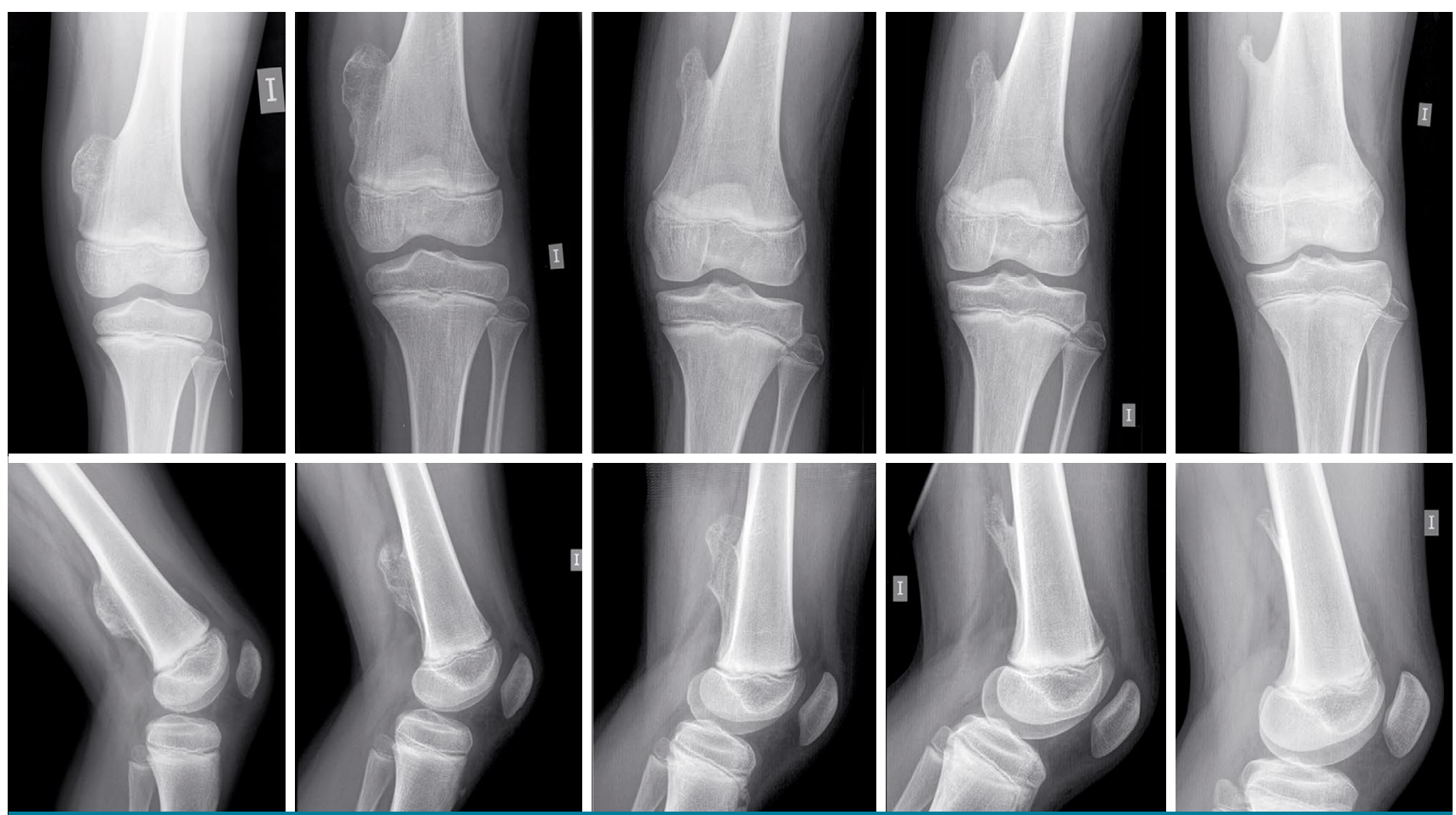

FIGURE 3. Anteroposterior and lateral X-rays of the left knee. A 10-year-old boy with an osteochondroma in distal femur followed by $X$-ray annually, until the age of 15 and the tumor almost vanished. 

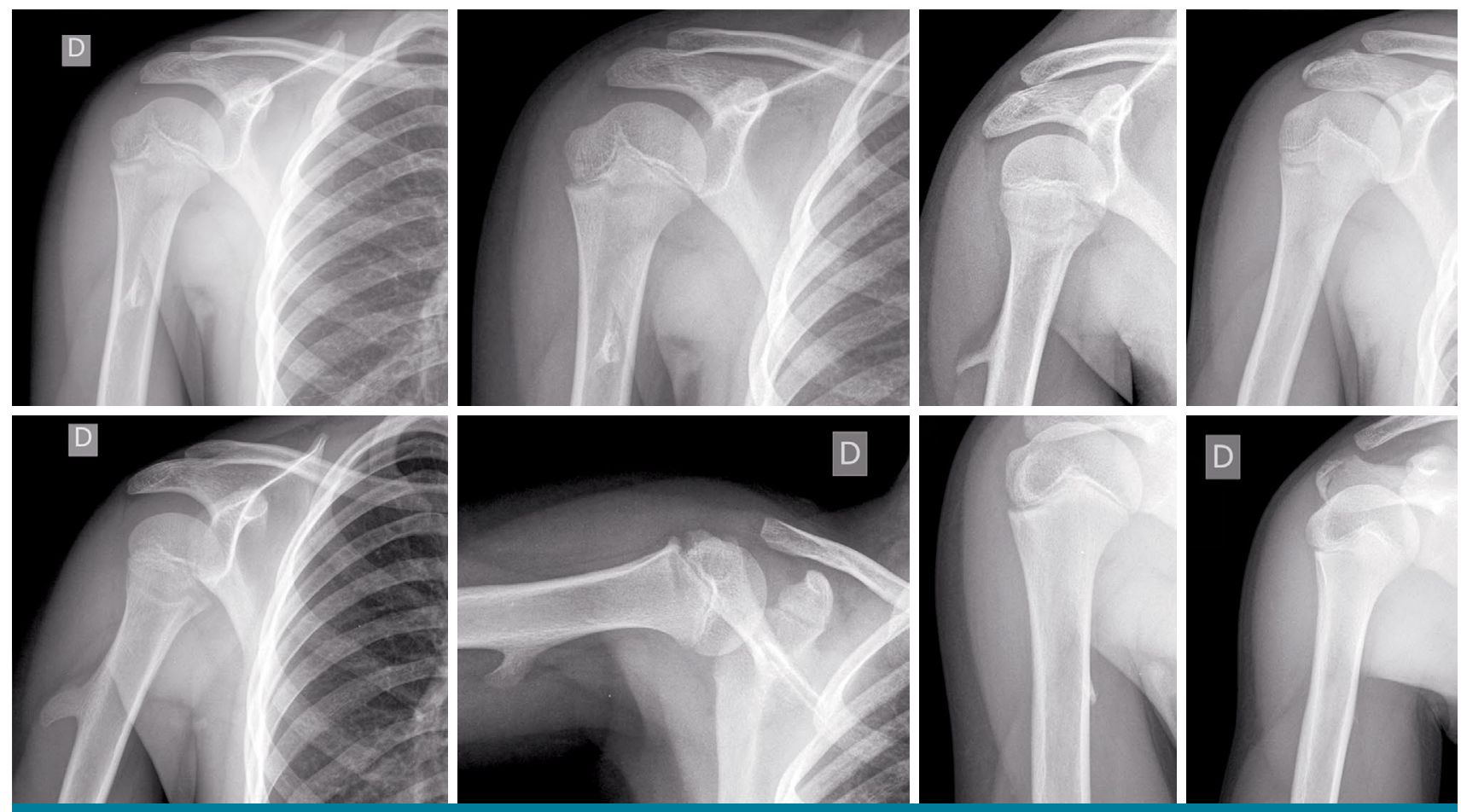

FIGURE 4. Anteroposterior radiographies of the right shoulder. An 11-year-old boy with an osteochondroma in proximal humerus followed by X-ray for four consecutive years.

\section{DISCUSSION}

According to Dahlin and Unni, ${ }^{[1]}$ osteochondromas represent $40 \%$ of benign tumors and $10 \%$ of primitive bone tumors, being more frequent in men (ratio: 1.5/1). ${ }^{[2]}$ Most of them are diagnosed in the second decade of life and usually stop growing after the closure of the bone physis, remaining commonly asymptomatic. ${ }^{[3]}$ Symptomatic forms usually manifest before the age of 20 years, being pain and bony mass detection the most common symptoms. ${ }^{[3]}$

Osteochondromas are observed in bones with endochondral growth, at the level of the metaphyseal aspect of the fertile growth cartilages, in flat bones, and those of the axial skeleton. The discovery of a diaphyseal exostosis assumes that the lesion has migrated during growth. ${ }^{[3]}$

Sarcomatous degeneration of solitary osteochondromas is uncommon, and is around 1\% of recognized exostoses. ${ }^{[1,4]}$ These cases are usually accompanied by clinical exacerbation and radiographic changes.

Osteochondromas are benign tumors that usually have a slow and painless progressive growth. However, spontaneous regression is an exceptional event. Conservative treatment with clinical and radiographic annual follow-up may be a possible approach. ${ }^{[5]}$

In most cases, radiographs are sufficient to establish the diagnosis and follow-up. ${ }^{[5-17]}$ Pathological diagnosis is not usually necessary. Nevertheless, Hoshi ${ }^{[18]}$ used computed tomography (CT) and Minami ${ }^{[19]}$ magnetic resonance imaging (MRI) to analyze the tumor. Deprez ${ }^{[20]}$ employed radiographs and high-frequency ultrasound studies to measure the size and thickness of the cartilaginous cap of the lesion.

For efficient radiation protection, particularly in children, we consider that CT studies should be restricted to doubtful X-ray images, rapidly growing lesions, neurovascular compromise or possible malignant degeneration. ${ }^{[21,22]}$ The study of the tumor cartilage cap or the surrounding soft tissues can be done combining X-ray with ultrasound, as it has a comparable value with CT. ${ }^{[23]}$

Magnetic resonance imaging is a valuable complementary test that can show specific characteristics of the cartilaginous cap of osteochondromas; however, the necessity of general anesthesia in children and its high cost make it a non-cost-effective tool for the diagnosis and 
follow-up of osteochondromas in children. Most osteochondromas can be diagnosed and followedup by simple X-ray. We recommend restricting ultrasounds, CT and MRI to doubtful X-ray images, rapidly growing lesions, neurovascular compromise or possible malignant degeneration.

According to the uncommon spontaneous regression of osteochondromas, we conducted a bibliographic research and rescued 16 case reports (Table I). Paling ${ }^{[6]}$ referred that osteochondroma natural history depended upon the temporal relationship between its own growth and that of the host bone. This regression apparently resulted from a cessation of growth of the osteochondroma prior to skeletal maturation, with subsequent incorporation of the lesion into the enlarging bony metaphysis. ${ }^{[6]}$ Copeland $^{[7]}$ was among the first to write about the

\begin{tabular}{|c|c|c|c|c|c|c|c|}
\hline \multicolumn{8}{|c|}{ TABLE I } \\
\hline Case report & Year & $\begin{array}{c}\text { No. } \\
\text { patients }\end{array}$ & Location & Sex & $\begin{array}{c}\text { Age at diagnosis } \\
\text { (year) }\end{array}$ & $\begin{array}{l}\text { Time until } \\
\text { regression } \\
\text { (year) }\end{array}$ & $\begin{array}{c}\text { Trauma } \\
\text { (Yes/No) }\end{array}$ \\
\hline Paling ${ }^{[6]}$ & 1983 & 1 & Distal femur & Male & 9 & 6 & No \\
\hline \multirow{2}{*}{ Copeland et al. ${ }^{[7]}$} & \multirow{2}{*}{1985} & \multirow{2}{*}{2} & Distal femur & Male & 11 & 1.5 & Yes \\
\hline & & & Distal femur & Male & 10 & 2 & Yes \\
\hline \multirow[t]{2}{*}{ Castriota-Scanderbeg et al. ${ }^{[8]}$} & \multirow[t]{2}{*}{1995} & \multirow[t]{2}{*}{2} & Distal radius & Male & 12 & 1 & Yes \\
\hline & & & Proximal humerus & Female & 5 & 3 & No \\
\hline Claikens et al. ${ }^{[9]}$ & 1998 & \multirow[t]{2}{*}{1} & Distal ulna & Male & 7 & 0.5 & No \\
\hline Yamamoto et al. ${ }^{[10]}$ & 2001 & & Proximal phalanx & Male & 3 & 7 & No \\
\hline Reston et al. ${ }^{[17]}$ & 2004 & 1 & Distal femur & Male & 15 & 4 & No \\
\hline Hoshi et al. ${ }^{[18]}$ & 2007 & 1 & Proximal humerus & Male & 7 & 1.25 & No \\
\hline Arkader et al..$^{[11]}$ & 2007 & 1 & Distal femur & Female & 12 & 6 & No \\
\hline Minami et al. ${ }^{[19]}$ & 2009 & 1 & Distal tibia & Female & 6 & 2 & No \\
\hline Valdivielso-Ortiz et al..$^{[12]}$ & 2010 & 1 & Distal femur & Female & 9 & 4 & No \\
\hline Mahmoodi et al. ${ }^{[13]}$ & 2010 & 1 & Proximal tibia & Female & 9 & 9 & No \\
\hline \multirow[t]{2}{*}{ Deprez et al..$^{[20]}$} & \multirow[t]{2}{*}{2011} & \multirow[t]{2}{*}{1} & Distal femur & Female & 11 & 4 & No \\
\hline & & & Humerus & Male & 6 & 3 & No \\
\hline \multirow{3}{*}{ Passanisse et al..$^{[5]}$} & \multirow{3}{*}{2011} & \multirow{3}{*}{4} & Humerus & Male & 7 & 5 & No \\
\hline & & & Humerus & Male & 10 & 2.5 & No \\
\hline & & & Distal femur & Male & 12 & 4 & No \\
\hline Hill et al..$^{[14]}$ & 2014 & 1 & Distal femur & Male & 6 & 3 & No \\
\hline \multirow[t]{4}{*}{ Heyworth and Rashid ${ }^{[15]}$} & \multirow[t]{4}{*}{2018} & \multirow[t]{5}{*}{1} & Distal humerus & Male & 1.25 & 0.25 & Yes \\
\hline & & & Distal femur & Male & 13 & 10 & No \\
\hline & & & Distal femur & Male & 13 & 5 & No \\
\hline & & & Distal fibula & Female & 13 & 3 & No \\
\hline \multirow{6}{*}{ Aiba et al. ${ }^{[16]}$} & \multirow{6}{*}{2018} & & Distal femur & Male & 14 & 4 & No \\
\hline & & \multirow{5}{*}{8} & Distal tibia & Male & 13 & 4 & No \\
\hline & & & Distal femur & Male & 16 & 3 & No \\
\hline & & & Distal femur & Male & 7 & 6 & No \\
\hline & & & Pelvis & Male & 12 & 5 & No \\
\hline & & & Distal femur & Male & 4 & 3 & No \\
\hline \multirow{3}{*}{ Our study } & \multirow{3}{*}{2021} & \multirow{3}{*}{4} & Proximal humerus & Male & 10 & 3 & No \\
\hline & & & Distal femur & Male & 10 & 5 & No \\
\hline & & & Proximal humerus & Male & 11 & 4 & No \\
\hline
\end{tabular}


spontaneous resolution of osteochondromas. In 1985, he published two cases located in the distal femur. Copeland considered that the regression of the lesions might be attributed to cessation of the growth of the cartilaginous cap, followed by active resorption. He also related it to the appearance of a fracture line at the base of the exostosis that may have compromised the growth of the cartilaginous cap or altered its vascular supply. The fracture may have also stimulated growth in the periosteal tissue which functionally, then, resembled a normal periosteum, capable of mediating increased remodeling. Castriota-Scanderberg et al. ${ }^{[8]}$ agreed with the Copeland's theory of bone resorption after exostosis fracture, since he presented a case with a similar pathogenesis. They suggested that, under the stimulus of trauma, the cells with osteogenic potencies in the periosteum became actively engaged in the remodeling of bone. In total, four of the cases revised mentioned a trauma antecedent ${ }^{[7,8,15]}$ that could have triggered the shrinkage of the tumor and reduce the time to its regression; however, due to the inaccuracy between the time of exostosis appearance and its diagnosis, the exact time of regression is uncertain. In relation to the regression modes described by Aiba, ${ }^{[16]}$ our cases were included in the incorporation theory, since the osteochondromas became mature before growth plate closure and were incorporated into bone growing in a vertical axis.

According to our bibliographic revision, we found 14 cases of osteochondroma regression in distal femur $(48.28 \%)$ and five in proximal humerus (17.24\%). These locations are the most commonly documented and this may be due to the higher incidence of osteochondromas in these areas. ${ }^{[24]}$ All the cases presented in our study were in those locations.

In the literature, the average age at the time of diagnosis is 9.61 (range, 1.25 to 16) years and 13.51 (range, 1.5 to 23) years at the time of resolution..$^{[5-16,18-20]}$ In our study, the average age at time of diagnosis was 8.75 (range, 4 to 11) years and 12.5 (range, 7 to 15) years at the time of resolution. In addition, the four cases we present follow a similar pattern: they are all males in the first or second decade of their lives who noticed an unpainful bony mass in their extremities (proximal humerus and distal femur). They were followed by clinical examination and X-ray annually, until osteochondroma vanished.

In conclusion, although the initial rapid growth of the osteochondroma makes surgery tempting, it may not be necessary at all. If local symptoms are not severe and there is no evidence of malignant degeneration, it is reasonable to delay intervention and follow a conservative treatment, taking into account that spontaneous regression of solitary osteochondromas may occur.

\section{Declaration of conflicting interests}

The authors declared no conflicts of interest with respect to the authorship and/or publication of this article.

\section{Funding}

The authors received no financial support for the research and/or authorship of this article.

\section{REFERENCES}

1. Dahlin DC, Unni KK. Osteochondroma (osteocartilaginous exostosis). In: Dahlin DC, Unni KK, editors. Bone tumors. 4th ed. Springfiel: CC Thomas; 1986. p. 18-32.

2. Campanacci $M$, editor. Bone and soft tissue tumors: clinical features, imaging, pathology and treatment. 2nd ed. Vienna: Springer-Verlang; 1999.

3. Gouin F, Venet G, Moreau A. Exostosis solitarias, exóstosis múltiple y otras exóstosis. In: O’Neill A, editor. Encyclopedie Médico-Chirurgicale. 1-9 editions. Paris: Elsevier; 2001. p. E-14-171.

4. Schajowicz F. Cartilage-forming tumors. In: Schajowicz F, editor. Tumors and tumorlike lesions of bone and joints. New York: Springer-Verlang; 1981. p. 124-34.

5. Passanise AM, Mehlman CT, Wall EJ, Dieterle JP. Radiographic evidence of regression of a solitary osteochondroma: A report of 4 cases and a literature review. J Pediatr Orthop 2011;31:312-6.

6. Paling MR. The "disappearing" osteochondroma. Skeletal Radiol 1983;10:40-2.

7. Copeland RL, Meehan PL, Morrissy RT. Spontaneous regression of osteochondromas. Two case reports. J Bone Joint Surg [Am] 1985;67:971-3.

8. Castriota-Scanderbeg A, Bonetti MG, Cammisa M, Dallapiccola B. Spontaneous regression of exostoses: Two case reports. Pediatr Radiol 1995;25:544-8.

9. Claikens B, Brys P, Samson I, Baert AL. Spontaneous resolution of a solitary osteochondroma. Skeletal Radiol 1998;27:53-5.

10. Yamamoto T, Kurosaka M, Mizuno K. Spontaneous resolution of a phalangeal solitary osteochondroma. J Hand Surg Am 2001;26:556-8.

11. Arkader A, Dormans JP, Gaugler R, Davidson RS. Spontaneous regression of solitary osteochondroma: Reconsidering our approach. Clin Orthop Relat Res 2007;460:253-7.

12. Valdivielso-Ortiz A, Barber I, Soldado F, Aguirre-Canyadell M, Enriquez G. Solitary osteochondroma: Spontaneous regression. Pediatr Radiol 2010;40:1699-701.

13. Mahmoodi SM, Bahirwani RK, Moosa NK, Eydou AZ, AbdullGaffar B. Spontaneous osteochondroma resolution in a young female: Imaging and histopathological findings. Med Princ Pract 2010;19:228-31.

14. Hill CE, Boyce L, van der Ploeg ID. Spontaneous resolution of a solitary osteochondroma of the distal femur: A case report and review of the literature. J Pediatr Orthop B 2014;23:73-5.

15. Heyworth PB, Rashid M. Regression of a solitary osteochondroma of the distal humerus in a toddler following trauma. Radiol Case Rep 2018;14:187-9. 
16. Aiba H, Yamada S, Yamamoto N, Hayashi K, Miwa S, Tsuchiya $\mathrm{H}$, et al. Spontaneous shrinkage of solitary osteochondromas. Skeletal Radiol 2018;47:61-8.

17. Reston SC, Savva N, Richards RH. Spontaneous resolution of solitary osteochondroma in the young adult. Skeletal Radiol 2004;33:303-5.

18. Hoshi M, Takami M, Hashimoto R, Okamoto T, Yanagida I, Matsumura A, et al. Spontaneous regression of osteochondromas. Skeletal Radiol 2007;36:531-4.

19. Minami S, Nakatani N, Miyazaki N, Watanuki A, Honda T, Yoshida M. Spontaneous regression of a solitary osteochondroma of the distal tibia. J Orthop Sci 2009;14:669-71.

20. Deprez FC, Beltrán-Marín M, Malghem J, Menten R,
Clapuyt R. Solitary osteochondroma: Spontaneous regression. JBR-BTR 2011;94:217.

21. Holmberg O, Malone J, Rehani M, McLean D, Czarwinski R. Current issues and actions in radiation protection of patients. Eur J Radiol 2010;76:15-9.

22. Chhem RK. Radiation protection in medical imaging: A never ending story? Eur J Radiol 2010;76:1-2.

23. Lin J, Wang W, Chen G, Chen C. Value of X-ray combined with ultrasound in the diagnosis and treatment of solitary osteochondroma. Nan Fang Yi Ke Da Xue Xue Bao 2013;33:1390-3.

24. Dahlin DC, Unni KK. Bone tumors. In: Unni KK, Carrie Y, editors. Dahlin's bone tumors. 6th ed. Philadelphia: Lippincott, Williams and Wilkins; 2010. p. 9-14. 